\title{
Endogenous Regional Development: Lessons from Languedoc-Roussillon and Montpellier
}

\author{
Niles Hansen*
}

\begin{abstract}
This article critically examines how the French Mediterranean region of Languedoc-Roussillon, and especially its capital, Montpellier, evolved from economic stagnation to a path of sustained economic development involving high-technology activities. The transformation is discussed in the context of the historical background of the region and of changes in French regional development policies. Attention is also devoted to such problems as the region's high unemployment rate despite its being the leader among all French regions in terms of various measures of economic progress.
\end{abstract}

\section{INTRODUCTION}

Theorists and practitioners concerned with regional development have increasingly realized that it is difficult to initiate sustained development in lessdeveloped areas through top-down policies and programs that provide various forms of assistance from the outside. Rather, effective regional and local efforts are required in order to achieve necessary structural changes in the economy and, often, in the mentalities that condition possibilities for change. This article critically examines how the French Mediterranean region of Languedoc-Roussillon evolved from economic stagnation to a path of sustained endogenous development, in large part through the remarkable expansion of its capital, Montpellier.

The following section outlines the national context within which the transformation of Languedoc-Roussillon has taken place. Next, the particular historical background of the region is presented. Attention is then devoted to the factors behind the emergence of Montpellier as a high-technology center and, more specifically, to the technopole development strategy that it has pursued. Consideration is next given to the reasons why Languedoc-Roussillon has not only the highest rate of in-migration among all French regions, but also the highest unemployment rate. Finally, there is an analysis of the nature and significance of issues concerning intraregional disparities and the role of French regions in the new Europe.

\section{THEORY AND PRACTICE IN FRENCH REGIONAL DEVELOPMENT}

France's efforts with respect to regional development planning evolved during the decades following World War II largely as a response to what was widely regarded as an overconcentration of population and economic activity in the Paris region and a concomitant neglect of the provinces. Between 1880 and 1936, the Paris region tripled in population size while the rest of the country experienced an absolute population decline. Between 1896 and 1936, industrial

*Professor, Department of Economics, University of Texas, Austin, TX. 
employment in France as a whole increased by 3 percent, but it rose by 45 percent in the Paris region. The national transportation network, which essentially radiated from the Paris hub to the neglect of direct linkages among provincial cities, provided a strong inducement for continuing concentration of business headquarters, higher education, financial institutions, and government in Paris.

During the 1950s some efforts were made to decentralize industry from Paris and to formulate regional development plans, but in fact little was accomplished in terms of genuine national economic decentralization. In the early 1960s, regional development policy was strengthened by the Gaullists. France was divided into 22 program regions, regional planning was brought into the national system of indicative planning, and an agency was created to encourage and coordinate regional dimensions of planning at various levels of government and in the national plans. In the Fifth Plan (1966-1970) the regions became directly involved in the national planning process for the first time. Priority was given to the expansion of industry in western France and to investments in nine provincial urban complexes (métropoles d'équilibre), whose expansion was intended to induce regional development and a more "balanced" national distribution of economic activity. The latter policy was clearly influenced by French growth pole theory.

The term "growth pole" was coined by François Perroux, though its spatial aspects were largely developed by Jacques Boudeville and others. The theory maintains that it is inefficient and ineffective to spread regional development funds thinly over large areas. Rather, development-oriented investments should be concentrated in a relatively few places (growth poles) with significant growth potential, thereby realizing scale and agglomeration economies. The expansion of the growth poles would be beneficial for the areas themselves, for migrants to them from regions lacking economic opportunity, and for the congested core area of the country (Paris) because migrants would be diverted away from it. In the longer run, development would spread from the growth poles to their respective peripheries, thus bringing about more spatially diffused national development.

For a time, growth pole theory inspired regional development efforts throughout the world, but in retrospect it has been largely regarded as a failure because there are few examples of its successful application. In fact, most nominal growth pole strategies never left the stage of paper plans, which in turn was a consequence of political problems. The majority of places that did not receive growth pole designation naturally opposed the strategy. In response, governments often designated ever more growth poles, which led to widely dispersed investments. And where investments were concentrated, they were often in the form of steel or petrochemical complexes with few local employment linkages. Finally, the growth pole strategy was criticized for being a centralized, top-down approach by those who favored greater local and regional participation in the planning process. All of these problems were to be found in France.

In the mid-1970s, after 30 years of nearly continuous expansion, the French economy entered a long period of high unemployment, with particularly adverse 
effects for older oligopolies in heavy industry. While older industries in the north declined, there was a remarkable expansion of small- and medium-sized enterprises in the south and west. At the same time there was a reversal of interregional population migration patterns in favor of the south and west, and especially the Mediterranean regions. A great deal of evidence indicated that migrants tended to be more influenced by quality of life considerations than by economic motives. Growth of industry and population in traditionally lagging regions produced a shift in regional policy, which now devoted relatively more attention to "solidarity" with northern industrial regions even though they typically still had higher per capita incomes.

When the Socialists came to power in 1981 they implemented measures to decentralize decision-making authority to the communes, departments, and regions. This coincided with a new emphasis in French regional economic theory on issues of endogenous development and the creation of innovative local and regional milieux. In fact, the reforms failed to create a strong regional system, and the regions have continued to lack the resources needed to adequately discharge their economic development responsibilities. For example, Michel (1994) points out that, taken as a whole, the budgets of the regions amount to less than those of the departments and, even more so, the communes. In some cases the budget of a department in a region is greater than that region's budget. In international terms, Michel (1994) indicates that in comparison with the budget for the Rhône-Alps region (whose core is Lyon, the second largest city in France), the budget for Lombardy (Milan) is 20 times as great and that for Baden-Württemberg (Stuttgart) is 70 times as great.

It is often argued that even if the 22 French regions had more financial resources at their disposal, they would still be too numerous to be effective in the new European Union context. In any case, some efforts at interregional cooperation are being made, both among French regions and even across international borders. Despite the inadequacies of the French governmental reforms, they have at least reduced resentment against Paris and given localities and regions a greater sense of being in control of their own destinies.

\section{LANGUEDOC-ROUSSILLION: THE HISTORICAL BACKGROUND}

The Languedoc-Roussillon region, which had 2.2 million inhabitants in 1995, includes a coastal plain along the Mediterranean Sea; the French part of Catalonia, which includes the eastern Pyrenees mountains; the Cévennes mountains in the northeast; and, in the north, a limestone plateaux of the southern Massif Central, an area rich in caves and gorges.

The Languedocian Plain is one of Europe's oldest through-routes for traders and invaders. It has been settled over time by Phocaeans from Greece, by Romans, and by Saracens, who had a strong influence on the civilization that blossomed in the eleventh and twelfth centuries when Languedoc was a powerful independent realm. In the early thirteenth century, the local Cathar (Albigensian) 
heresy was cruelly suppressed in a campaign that mixed religious crusade with imperial expansion on the part of the King of France. Ardagh (1991, p. 210) has observed that "Even today, these events have not been forgotten or forgiven by people of Languedoc, where tribal memories run deep and resentment against Paris persists." Indeed, for centuries after the Cathar suppression the langue d'oc, rather than French, continued to be spoken in the south. Although the popularity of what was to become the French national anthem was assured by a battalion of volunteers from Marseilles who entered Paris singing their song, according to Davies (1996, p. 718), "there is some doubt whether the battalion of volunteers from the Midi could actually have spoken French." Even as recently as 1860, nearly no one spoke French in most of what is today the Languedoc-Roussillon region (DATAR 1988, p. 318).

The industrialization of France in the nineteenth century and first twothirds of the twentieth century had little impact on Languedoc-Roussillon, though this was also the case for numerous other regions of the south and west. During the two decades following the World War II, when the French economy was restructuring, expanding, and essentially without unemployment, LanguedocRoussillon was regarded as a relatively poor region, characterized by low wages, net outmigration and a lack of innovation (Laget 1993). Because it was so easy to produce wine in the region - it accounted for 40 percent of all French wine production and most of its cheaper wine - there was little incentive to engage in more entrepreneurial activities (Ardagh 1991). Montpellier was endowed with an old and venerable university, but its programs were oriented toward medicine, public administration, commerce, and the liberal professions. These were the "givens" in national regional planning with respect to Languedoc-Roussillon. However, fundamental changes were about to occur, particularly with respect to Montpellier.

\section{THE ASCENDANCE OF MONTPELLIER}

In 1962, Algeria was granted its independence from France. Some 800,000 North African settlers were repatriated to France, mostly to the south owing to its familiar Mediterranean environment. Montpellier received 13,000 new inhabitants immediately after Algerian independence, and more were to follow. To cope with this influx, a satellite suburb with 10,000 housing units was created. The repatriates, who were typically industrious and often possessed resources, brought a new spirit of enterprise to the city (Guides Bleus 1996; Marchesnay 1985)

A further major impetus to Montpellier's economic vitality came in the mid-1960s with the arrival of an IBM plant designed to produce the company's largest mainframes for the whole of Europe. The plant eventually employed 3,000 persons, of whom 600 were engineers. The IBM facility marked a major turning point not only in its own right, but also because it induced a network of related activities and generated a large body of highly qualified personnel receptive to 
innovation (District de Montpellier 1988). IBM brought from Paris a number of subcontractors, five of which employed over 100 persons locally. Other subcontractors that owed their existence to IBM were located both in Montpellier and in other towns in Languedoc-Roussillon (Brunet et al. 1988). Spin-off activities encouraged by IBM were also successful. IBM's tight quality control put constant pressure on its partners to continually develop their technical skills and knowhow, which in turn brought the partners orders from many other large industrial enterprises, some of which were engaged in sensitive, highly sophisticated defense projects.

As a result of these activities, the traditional conservative practices that had characterized businesses in Montpellier were radically transformed by a new appreciation for high-technology industry, entrepreneurs, and interfirm networking. A great deal of professional education was also reoriented to conform to the needs of the new dynamic firms in sectors previously unknown in Montpellier (Ferras and Volle 1988). Between 1975 and 1984, the electrical equipment and electronics sectors in Languedoc-Roussillon experienced an employment increase of 85 percent, to 8,000 employees in 1984 (Fornairon 1987). Between 1980 and 1983, the region ranked fourth among all French regions with respect to net (births minus closings) new high-technology firms created (Uhrich 1987). In 1988, the premier French economic magazine rated the economic dynamism of the 55 French urban agglomerations with more than 100,000 inhabitants on the basis of 18 criteria (L'Expansion 1988). Montpellier ranked at the top.

The arrival of industrious repatriates from North Africa and of the IBM establishment were certainly fortuitous events in the economic history of Montpellier, but it may be argued that these were not sufficient conditions for the relatively sudden and remarkable development of the city. Outside observers have indeed attributed much of the dynamism to cultural factors. For example, in their analysis of the evolution of European urban centers, British researchers argue that in such cities as Milan, Lyon, and Birmingham, a sense of rivalry with national capitals has served to focus local decision making on their local needs and opportunities with respect to economic development. But they maintain that in terms of interactions between development and strong sense of regional culture, "The deep south culture of Montpellier is the best example" (Parkinson and Harding 1995, p. 73). A Swiss study of economic restructuring in Montpellier similarly concludes that "the process that leads to the quest for a regional identity is indisputably at work" (Maillat 1990, p. 238). Although these assertions are not developed in any detail, it is evident that efforts to maintain a distinct regional culture and a resistance to Paris have a long history in Languedoc-Roussillon.

The Cathar experience, an affinity with the Protestant Reformation (Montpellier and Nîmes, in particular, still have a highly influential Protestant minority), the long dominance of the langue d'oc (which is still extant among older people in rural areas), and the idealistic though small movement to create an Occitan nation in the southwest all testify to a strong regional consciousness. 
Of course, regional grievances and resentments do not necessarily imply an impetus to regional economic development, as witnessed by the long economic torpor of Languedoc-Roussillon. Even as recently as the late 1950s and 1960s, large segments of the regional population reacted angrily to major national government development projects for the region (Ardagh 1991). One, intended to encourage tourism, constructed a chain of eight large modern resort complexes along the Mediterranean coast. The other involved the creation of a wide irrigation canal that was dug westward from the Rhone River. As an integral part of this undertaking, wine producers were encouraged to uproot some of their vines and switch to other types of agricultural production. Resistance to these endeavors was in many respects a reaction to the top-down regional planning of the period; local persons were scarcely consulted by planners in Paris. Meanwhile, wine producers continued to expect to be subsidized for falling prices when bumper harvests resulted in wine surpluses.

Fortunately, regional pride was harnessed for more constructive purposes as Montpellier began to develop. This could be seen not only in the economic sphere, but also in creative urban planning. In the historic central district of Montpellier, restoration projects were undertaken and zones of traffic-free streets and plazas promoted an animated social life. Large-scale building projects in the center complemented the historic core and provided first-class sites for conventions and performances by artists of international caliber. This enhancement of the quality of life has been not only valuable in its own right, but has also made the city still more attractive to highly qualified workers.

\section{THE MONTPELLIER L.R. TECHNOPOLE STRATEGY}

In the mid-1980s, a consensus formed in Montpellier to promote the local economy by highlighting its scientific and technical potentials, without resorting to the exemptions and subsidies that many less-developed communities have offered in order to attract industry. The association created to implement this program is known as Montpellier L.R. Technopole (MLRT), the "L.R" indicating an effort to cooperate with other localities in Languedoc-Roussillon. The Administrative Council of the MLRT is composed of representatives from commerce and industry, banks and other financial institutions, local government, research laboratories, universities, and regional advisory organizations. The principal objectives are to facilitate the introduction of new technologies into existing firms, to provide comprehensive assistance to newly arriving establishments, and to promote the creation of small- and medium-sized enterprises.

In 1988, when Montpellier had 45,000 students and 3,000 university and private researchers, Georges Frêche, who was and still is the mayor, and who has been highly instrumental in all that pertains to Montpellier's development, maintained that "All the centers of 'grey matter' generate employment. To deny this fact is like trying to stop the sea with sand castles" (Bécriaux 1988). Building on this grey matter, the MLRT strategy has emphasized five technical areas, or poles, 
in which Montpellier already had a competitive advantage. Heliopolis is concerned with the promotion of tourism and cultural activities. Euromédicine, the medical, pharmaceutical, and biotechnology pole, is based on the oldest medical school in Europe, and on the Faculty of Pharmacy, the second most important in France. It includes 15,000 students in medicine, pharmacy, and dentistry, 2,000 researchers, a science park with 4,000 employees, and organisms to promote the commercialization of promising research results. Agropolis provides a focus for Europe's largest concentration of research on tropical and Mediterranean agronomy. It consists of 21 higher education facilities, institutes, and research enterprises, with over 2,000 researchers and students. The Antenna pole has been concerned with all aspects of telecommunications and audiovisual techniques, including the development of a fiber optic cable system covering the whole of the Montpellier agglomeration; the creation of a teleport; and research on geographic information systems, long-distance teaching via telecommunications, computeraided design, and new modes of telecommunications. Finally, the Informatique pole has built upon IBM's introduction of high-technology industry to Montpellier. Here various institutes carry out research in the fields of microelectronics, data processing, robotics, artificial intelligence, and information networks.

The term "technopole" has been used in connection with firms, science parks, or collections of laboratories. It has also been used to describe only genuinely innovative technological parks. In the case of the MLRT strategy, it is the whole metropolitan area that is the technopole, which integrates higher education, research centers, and private enterprises within a context that provides high quality-of-life standards.

How well has the MLRT strategy succeeded? In 1993, the national Institute for Statistics and Economic Studies (INSEE) analyzed the degree of strategic employment in French cities. Strategic employment was defined to be employment that represented a high level of qualification and that performed a development-inducing function, such as business executives, engineers, researchers, and (with perhaps a uniquely French appreciation) artists and artisans of art (Alberti 1994). In terms of strategic employment as a proportion of the work force, Montpellier (11.2 percent) ranked behind only Paris (15.2 percent) and Grenoble (11.3 percent). In 1996, this index, along with 10 others that provided an indication of local "dynamism and development," was used by the business magazine Challenges (1996) to rank French cities according to this criterion. Montpellier was the top-ranked city, and special mention was made of its large and dynamic student population. The University of Montpellier accounts for 63,000 students, and another 20,000 students pursue their advanced education in a variety of schools and institutes (INSEE Languedoc-Roussillon 1996). Owing to its already existing excellence, the University of Montpellier, along with four other universities outside of the Paris region, has recently been chosen by the national government for further development as an institution of importance on a European scale (Michel 1994). 


\section{MIGRATION, EMPLOYMENT, AND UNEMPLOYMENT}

Between 1982 and 1990, Languedoc-Roussillon had the highest rate of inmigration among all French regions. During the 1980s it regularly ranked second in the creation of private nonfarm employment, and in 1993 it ranked first (Fornairon 1995). Between 1968 and 1990, the last year for which census data are currently available, the population of Languedoc-Roussillon grew from 1.71 million 2.12 million, which represented a growth rate of 24 percent, almost twice that for France as a whole (INSEE 1994). In-migrants to the region amounted to 258,240 between 1968 and 1975; 304,324 between 1975 and 1982; and 353,075 between 1982 and 1990. The corresponding net migration numbers are 84,385; 169,540; and 189,338 (Le Sage 1993a, 1993b). Languedoc-Roussillon consistently had net inmigration from all other regions, with the largest population shifts occurring with neighboring regions as well as the Paris region. The Hérault department, which includes Montpellier, grew in population from 706,000 in 1982 to 795,000 in 1990, and to an estimated 854,000 in 1995 (INSEE 1996). Montpellier, which had a population of only 97,000 in 1954, now has approximately 400,000 inhabitants within its metropolitan labor basin, and four out of five are not originally from the city.

It might be supposed that economic factors have been attracting migrants to Languedoc-Roussillon, but this is not evident from data concerning the gross regional product, wages and salaries, or unemployment (Berger et al. 1988). To the extent that manufacturing engenders greater productivity than other sectors, Languedoc-Roussillon is at a disadvantage because it is the least industrialized region in France and is becoming even less so. Manufacturing accounted for only 16 percent of regional employment in 1975 and for only 13 percent in 1990 (INSEE 1996). In 1992, Languedoc-Roussillon had 3.7 percent of the French population but accounted for only 2.9 percent of the national GDP, though given the economic weight of Paris it may be more appropriate to compare Languedoc-Roussillon with France excluding the capital region. In this context, Languedoc-Roussillon accounted for 4.6 percent of the population and for 4.1 percent of the provincial gross regional product (Fornairon 1995). A further consideration is that Languedoc-Roussillon has a relatively low labor force participation rate: in 1990 it was 48.9 percent, whereas that for the nation was 54.6 percent (INSEE 1996). Taking this into account, in 1982 the gross regional product per person in the labor force was 1.3 percentage points above the national average, though by 1992 the corresponding value was 3.3 percentage points below (Fornairon 1995). In 1995, the average annual income from wages and salaries after taxes was 110,400 FF in Languedoc-Roussillon, 124,700 FF in France as a whole, and 113,200 FF in France excluding the Paris region. In the same year, when the unemployment rate was 11.7 percent in France, it was 16.1 percent in Languedoc-Roussillon (the highest among French regions, which has been the case since the 1980s) and 17.7 percent in the Herrault department (INSEE 1996).

Fornairon (1995) argues that these attributes of the Languedoc-Roussillon economy are attenuated by a number of factors and suggests that migration to the 
region is characterized by an investment in human capital that accepts short-term costs for a return on investment over a lifetime. Because so much employment and income in the region are derived from agriculture, tourism, construction, and services, it is reasonable to believe that there is a large underground economy, an economy of resourcefulness (la débrouillardise). For example, LanguedocRoussillon ranks higher with respect to bank deposits than with respect to the official gross regional product or the official average of wages and salaries. Moreover, consumption expenditures per household are the highest in France, with the exception of the Paris region. As to unemployment, it may represent a crisis or it may be a by-product of rapid growth. A dynamic regional economy with an entrepreneurial spirit and flexibility greatly facilitates not only adaptation on the part of firms, but also on the part of workers, who can experiment with unsteady jobs while waiting for the ones they really want. Also, if the risk of being unemployed in Languedoc-Roussillon is relatively high, the average duration is two weeks less than the national average (Laget 1993).

Despite a popular notion that Languedoc-Roussillon attracts persons who would rather be idle in the sun than in the north, a survey of adult in-migrants to the region indicated that 83 percent of them had a job when they arrived and only 9 percent were unemployed (Billaudel 1984). About half of the migrants were transferred by their employer, and these transfers were more often requested than proposed or imposed by the employer. Moreover, although the population of Languedoc-Roussillon has the highest level of educational attainment of any region, 18.0 percent of the migrants had a university education, compared with 5.4 percent of the total working population aged 15 to 54 years.

While some in-migrants have been returning to Languedoc-Roussillon to regain proximity to their families, various studies of labor mobility have shown that in-migrants in general typically are informed about their destination and do not simply part toward the unknown. Knowledge concerning economic conditions is supplemented by knowledge concerning the quality of life, including mountains, sea, and sun, but also urban amenities, which have been shown to be important to enterprises considering relocation to Languedoc-Roussillon (Fornairon 1995). Montpellier in particular offers clear advantages in this regard within the French context as a whole. Among the 29 largest cities outside of Paris, Montpellier ranks fourth with respect to visitors to fairs and exhibitions; second with respect to the provision of social and economic infrastructure; and first with respect to the number of cinemas, theaters, and museums per capita. In the last category, the Languedoc-Roussillon city of Nîmes took second place nationally (Challenges 1996).

Although the Montpellier metropolitan area accounted for 19 percent of the total population of Languedoc-Roussillon in 1995, rural areas still accounted for 37 percent. Between 1990 and 1995, the rural population increased from 783,000 to 813,000 and the relative growth of rural areas increased between the 1982-1990 and 1990-1995 periods (INSEE 1996). No matter where they settle in the 
region, new migrants from other regions have similar characteristics with respect to age, education, and professional status. However, new migrants to rural hinterlands, often in the mountains, are characterized by a high degree of individualism and independence. Their migration typically involves a change in type of home, from an apartment to a free-standing house; a change from salaried employment to independent activity; a type of work that can be done at home; and the development of an underground economy. They are attracted less by economic factors than by the geographic milieu, more fluid social structures, more flexible work hours, and the lifestyle that new migrants create among themselves. Increasingly, migrants to rural areas organize their work so that they do not have a total rupture with their previous employment. By utilizing computers and telecommunications they can continue to be partners or subcontractors with former employers (Catanzano 1987; Negro 1995).

\section{CURRENT ISSUES: THE REGIONAL, INTERREGIONAL, AND EUROPEAN CONTEXTS}

The old quarrels over which French cities should be designated as growth poles has had a counterpart in disputes concerning which cities should be the capitals of the regions, and resentment against Paris has had its counterpart in local resentments against regional capitals. In Languedoc-Roussillon, the transformation of Montpellier into the regional capital, the transfer of branches of national government agencies to Montpellier from other regional cities, and Montpellier's rapid expansion have been contested in the rest of the region, where important segments of the population believe that their localities have been harmed in the process (Guides Bleus 1996).

The MLRT development strategy did envisage the involvement of other regional cities to the benefit of the entire regional economy. However, Montpellier accounts for three-fourths of regional research employment, with the other onefourth diffused over 17 localities (Michel 1994). Between 1982 and 1990, the growth rate in "strategic employment," discussed previously, was 71 percent in Montpellier. In the next seven largest cities of the region the corresponding rates varied between 15 percent and 41 percent, with the average being 26 percent (Alberti 1994).

In the political realm, for many years after World War II, LanguedocRoussillon voted left; many towns were even governed by Communists. But in the 1980s there was a swing to the right, and since then the main tensions have not been as much Paris-directed as maintained within the region between the rightist regional assembly and Georges Frêche, Montpellier's assertive Socialist mayor (Ardagh 1991). Frêche (1997) recently attacked the regional authorities for failure to take advantage of the MLRT strategy, to utilize available central government programs, to undertake any major development project, to promote tourism and exports (including the region's much-improved wines), and to adapt education to the needs of the economy. 
In fact, there is little evidence that the positive economic externalities and scale economies in the Montpellier area have resulted in stagnation in the rest of the region, and if there are problems in this regard they have been offset by a significant degree of rural renovation (Fornairon 1993). For example, in Lozère, the most rural department, the unemployment rate in 1995 was only 6.3 percent, about a third of the regional rate (INSEE 1996). Moreover, the geographic area of Languedoc-Roussillon is one-fourth that of the Austin, Texas metropolitan area, which is considered to be intraregionally interdependent. Allowing that distances do not mean the same thing in France as in Texas, and given that both the Austin metropolitan area and Languedoc-Roussillon are marked by internal political squabbles, it still seems evident that the departments of Languedoc-Roussillon are economically interdependent.

The geographical size of Languedoc-Roussillon, which is about average for all French regions, is part of the more general problem of the size of French regions when considered in a European context. In 1961, a group of experts working for the European Economic Community proposed a regional division of Europe that included nine French regions, rather than the 22 created by the French government. French nationalists, who carried the day, objected that if larger regions were created they would become too independent of central authority, and that an integrated Europe would result in a disintegrated France (Hansen 1968). Ardagh (1991) maintained that to be truly effective in the new Europe, the 22 regions should be reduced to 12 by combining those that have affinities with one another. In 1992, the government gave the regions the option to associate in "interregional understandings" that would have such competencies as would be granted by the regions, but not taxing authority (Michel 1994). In 1997, the government proposed the creation of seven superregions (plus one representing the overseas territories) for elections of representatives to the European Parliament. It was argued that this would give the regions a stronger role in obtaining project funds from the European Union, but others maintained that it would be too complex to add a new layer of electoral geography to the old ones (de Bresson 1997). An obvious solution would be to transfer the powers of the 22 regions to the proposed seven regions.

In the past, the central government gave little encouragement to cooperation between French regions and their neighbors across the national boundary because such attempts at "microdiplomacy" were viewed as a possible threat to the foreign policy prerogatives of the nation-state. Today this attitude has been relaxed, so that French regions are free to cooperate with foreign regional entities as well as with other French regions (Conseil Economique et Social 1997). In response, Languedoc-Roussillon and the Midi-Pyrénées region, whose capital is the aerospatial center of Toulouse, are engaged in a project of cooperation with neighboring Catalonia, in Spain (or, as advertisements in the United States for the Barcelona Olympic games put it: "Catalonia is a country in Spain."). To date, this European project has yielded an agreement to cooperate in several fields, trans- 
portation in particular, and the publication of an essentially descriptive atlas of the regions concerned (Région Languedoc-Roussillon 1995). There is no reason to doubt that new initiatives will be forthcoming as Montpellier and Toulouse continue "to look across the Spanish border to Barcelona rather than northward to distant Paris" (Delamaide 1995).

\section{SUMMARY AND CONCLUSIONS}

Prior to the 1960s, Languedoc-Roussillon was a somnolent agricultural region with net out-migration, more concerned with long-held grievances against Paris than with transforming economic and mental structures. In the 1960s, the region was not included in the national government's growth pole strategy for provincial development because it was not deemed to have sufficiently high development potential. Nevertheless, by the 1980s Languedoc-Roussillon would, among all French regions, have the highest rates of growth of population, total employment, services employment, and, except for neighboring Provence, per capita gross disposable income. Though the region was still the least industrialized, it now possessed a rapidly growing high-technology sector. If the unemployment rate was also the highest in France, it could be argued that this problem was more related to the dynamics of rapid growth than to the kind of long-term structural difficulties found in the old indùstrial regions of northern France.

The remarkable transformation of Languedoc-Roussillon has to some extent been related to central government programs and policies. Thus, the development of coastal resorts has increased income from tourism and the construction of an irrigation infrastructure has resulted in greater agricultural diversification. More general measures to diffuse some powers once held in Paris have also given regions and localities a new sense of control over their own destinies. However, the major development-inducing innovations in Languedoc-Roussillon have come from within the region. In particular, if the location by IBM of an important facility in Montpellier provided an initial impetus to change, the consequent evolution of the city into a prominent center of high-technology activities was a result of concerted local efforts and a comprehensive and consistent development strategy. The presence of urban and environmental amenities and a relatively highly educated population have also been significant. Although expansion within Languedoc-Roussillon has been uneven, there is little evidence that Montpellier's ascendancy has been detrimental to other communities.

In the context of the European Union, Languedoc-Roussillon and the other French regions are probably too small to effectively carry out their development responsibilities, for which they have very limited resources in any case. In the future there are likely to be more concerted efforts to replace the existing regions with larger ones and to encourage international cooperation among border regions. Steps in this direction are already to be seen in initiatives recently undertaken among Languedoc-Roussillon, Midi-Pyrénées, and Catalonia to coordinate their development efforts. 


\section{REFERENCES}

Alberti, J. "Emploi Stratégique et Villes du Languedoc-Roussillon" Repères No. 12 (1994), 27-34.

Ardagh, J. Cultural Atlas of France. New York: Facts on File, 1991.

Bécriaux, R. “Technopoles, Villes Intelligentes." Le Monde, October 9, 1998, 14.

Berger, A., et al. La Revanche du Sud. Paris: Harmattan, 1988.

Billaudel, M. "Migration et Activité en Languedoc-Roussillon." Revue de l'Economie Méridionale No. 127 (1984), 23-34.

Brunet, R., et al. Montpellier Europole. Montpellier: Reclus, 1988.

Catanzano, J. Retour vers l'Arrière-Pays. Montpellier: Cahier de l'Economie Mèridionale, 1987.

Challenges. May, 1996.

Conseil Economique et Social. "Les Régions Frontalières: Situation Economique et

Cooperation Internationale." Problémes Economiques January 29 (1997), 6-11.

DATAR. Atlas de l'Aménagement du Territoire. Paris: La Documentation Française, 1988.

Davies, N. Europe. Oxford: Oxford University Press, 1996.

de Bresson, H. "Michel Barnier Propose la Régionalisation du Scrutin Européen." Le Monde, March 14, 1997, 11.

Delamaide, D. The New Superregions of Europe. New York: Penguin Books, 1995.

District de Montpellier. Montpellier L.R. Technopole. Montpellier: District de Montpellier, 1988.

Ferras, R., and J.-P. Volle. "Dire et Construire la Technopole MonpellierLanguedoc Roussillon." Etudes sur l'Hérault No. 4 (1988), 165-70.

Fornairon, J.D. "La Mutation des Activités et des Emplois." Revue de l'Economie Méridionale 35 (1987), 31-56.

"Montpellier et le Désert Languedocien." Paper presented at the University of Catane, Italy, September 1993.

. "Les Migrations Internes: Un Investissement?" Paper presented at the University of Algarve, Portugal, October, 1995.

Frêche, G. "L'Incompetance Régionale, Principal Cause du Surchomage en Languedoc-Roussillon." Puissances February (1997), 2-3.

Guides Bleus. Languedoc-Roussillon. Paris: Guides Bleus, 1996.

Hansen, N. French Regional Planning. Bloomington: Indiana University Press, 1968. Institut National de la Statistique et des Etudes Economiques (INSEE). Tableaux de l'Economie du Languedoc-Roussillon1993-1994. Montpellier: INSEE, 1994. . Tableaux de l'Economie du Languedoc-Roussillon1996-1997. Montpellier: INSEE, 1996.

. Languedoc-Roussillon. Tableaux de l'Economie du Languedoc-Roussillon. Montpellier: INSEE Languedoc-Roussillon, 1996.

Laget, M. “Le Languedoc-Roussillon: Région Expérimentale des Liens Croissance-

Emploi-Formation." Revue de l'Economie Méridionale 41(1993). 63-77.

Le Sage, G. “L'Immigration en Languedoc-Roussillon.” Réperes No. 12 (1993a), 11-14. 
. “Tendance Récente de l'Emigration Régionale." Réperes No. 12 (1993b), 15-18.

L'Expansion. September 22 (1988), 51-69.

Maillat, D. "Regional Restructuring in French-Speaking Europe." In W.B. Ströhr (ed.) Global Challenge and Local Response. London: United Nations University, 1990.

Marchesnay, M. "Petite Entreprise, Services et Région." Revue de l'Economie Régionale 33 (1985), 79-86.

Michel, M. L'Aménagement Régional en France. Paris: Masson, 1994.

Negro, Y. "L'Héritier, le Natif, et le 'Néo'." Revue de l'Economie Méridionale 43 (1995) 39-58.

Parkinson, M., and A. Harding. "European Cities Toward 2000: Entrepreneurialism, Competition, and Social Exclusion." In M. Rhodes (ed.) The Regions and the New Europe. Manchester: Manchester University Press, 1995.

Région Languedoc-Roussillon. Atlas de l'Eurorégion. Montpellier: GIP Reclus, 1995. Uhrich, R. La France Inverse? Paris: Economica, 1987. 